\title{
EL NACIMIENTO DEL “LIBERFASCISMO"Y LOS DISTINTOS MODOS DE GESTIÓN DE LA PANDEMIA EN AMÉRICA LATINA
}

\author{
THE BIRTH OF "LIBERFASCISM" AND THE DIFFERENT WAYS OF MANAGING THE \\ PANDEMIC IN LATIN AMERICA
}

\section{O NASCIMENTO DO “LIBERFASCISMO” E AS DIFERENTES FORMAS DE GESTÃO DA PANDEMIA NA AMÉRICA LATINA}

\author{
Jesús Ayala-Colqui \\ (Universidad Científica del Sur) \\ yayalac@cientifica.edu.pe
}

Recibido: 20/11/2021

Aprobado: 14/01/2022

\begin{abstract}
RESUMEN
El presente artículo se propone investigar la relación entre las distintas formas de gobierno de Latinoamérica y los modos de gestión social de la pandemia de la Covid-19. Para ello se realiza una distinción teórica entre neoliberalismo, neofascismo y "liberfascismo", concepto teórico acuñado ad hoc que describe la emergencia de grupos de extrema derecha, a fin de caracterizar las posturas políticas de los gobiernos en América Latina, especialmente, en los países de Chile, Perú y Brasil. Posteriormente, se analiza las estrategias de gobierno llevadas a cabo por cada tipo de gobierno con el recurso a las nociones de viropolítica (Ayala-Colqui, 2020b) y necropolítica (Mbembe, 2011). Finalmente, se reflexiona sobre la posible expansión del liberfascismo y los grupos de ultraderecha en la región, el cual tuvo como catalizador contextual las medidas restrictivas de confinamiento ejercidas durante la pandemia.
\end{abstract}

Palabras clave: COVID-19. ultraderecha. neoliberalismo. neofascismo. liberfascismo. necropolítica.

\section{ABSTRACT}

This article aims to investigate the relationship between the different forms of government in Latin America and the modes of social management of the Covid-19 pandemic. To do this, it introduces a theoretical distinction between neoliberalism, neofascism and "liberfascism", a theoretical concept coined ad hoc that describes the emergence of extreme right-wing groups, to characterize the political positions of governments in Latin America, especially in the countries of Chile, Peru, and Brazil. Subsequently, it analyses the government strategies carried out by each type of government using the notions of viropolitics (Ayala-Colqui, 2020b) and necropolitics (Mbembe, 2011). Finally, it reflects on the possible expansion of liberfascism and far-right groups in the region, which had as a contextual catalyst the restrictive confinement measures exercised during the pandemic.

Keywords: COVID-19. far-right. neoliberalism. neofascism. liberfascism. necropolitics. 
Este artigo tem como objetivo investigar a relação entre as diferentes formas de governo na América Latina e os modos de gestão social da pandemia de Covid-19. Para tanto, introduz uma distinção teórica entre neoliberalismo, neofascismo e "liberfascismo", conceito teórico cunhado ad hoc que descreve o surgimento de grupos de extrema direita, a fim de caracterizar as posições políticas dos governos na América Latina, especialmente na os países do Chile, Peru e Brasil. Posteriormente, analisa as estratégias de governo realizadas por cada tipo de governo a partir das noções de viropolítica (Ayala-Colqui, 2020b) e necropolítica (Mbembe, 2011). Por fim, reflete sobre a possível expansão do liberfascismo e de grupos de extrema direita na região, que teve como catalisador contextual as medidas restritivas de confinamento exercidas durante a pandemia.

Palavras-chave: COVID-19. extrema direita. neoliberalismo. neofascismo. liberfascismo. necropolítica.

\section{Introducción}

La pandemia de la Covid-19, sobre todo en su dos primeros años con las variantes alfa, beta, gamma y delta en auge (es decir, antes de la posibilidad de inmunizaciones masivas), trajo consigo, además de las cifras dramáticas de contagiados y fallecidos ${ }^{1}$, una miríada de interpretaciones teóricas. Entre estas resaltan las que giran en torno al concepto de biopolítica. Agamben (2020a) fue sin duda el abanderado de este tipo de conceptualizaciones: sus publicaciones fueron inclusive previas y/o simultáneas al inicio de los confinamientos alrededor del globo en los primeros meses del 2020. Retomando sus constructos teóricos previos (Agamben, 1998; 2003; 2008), el italiano postuló que la Covid-19 no era más que una "gripe normal" (normale influenza) que funcionaba dentro de una estrategia política de instalación de un persistente "estado de excepción" (Agamben, 2020a). Añadió luego que esta excepcionalidad traía una "bioseguridad" que limitaba todo albedrío individual (Agamben, 2020b, 2020d), tanto cuanto erigía a la ciencia como la "verdadera religión" (vera religione) (Agamben, 2020c). Una diversidad de textos hizo eco, de una u otra forma, de la posición de Agamben, sea prolongando o reformando sus análisis (Hillani, 2021; Kaya, 2021; Manichkin, 2021). A esta postura caracterizada por abordar la pandemia desde un punto de vista exclusivamente gubernativo en sus efectos epidemiológicos, de la cual Agamben hace las veces del epítome exegético, podemos denominarla "clave hermenéutica biopolítica".

Este primer modelo interpretativo adolece, empero, de dos elementos esenciales: por un lado, utiliza conceptos prefabricados para una situación inédita que no hacen sino simplificar su complejidad, toda vez que no solo se desplegaron dispositivos biopolíticos para la gestión de la peste, sino también legales, anatomopolíticos y algorítmicos; por otro lado, ignora radicalmente o en su defecto relativiza esencialmente la correlación entre técnicas de poder y fenómenos económicos, verbigracia, el mantenimiento de un modo de producción orientado hacia la valorización privada del capital (AyalaColqui, 2020b). De ahí la postulación alternativa del término "viropolítica" (viropolitics) para pensar, a la vez, la tesitura inesperada del acontecimiento pandémico, así como su funcionalidad respecto a la acumulación capitalista:

the full definition of viropolitics is: The updating and rearticulation of legal, disciplinary, security and algorithmic apparatuses, in the context of the management (social adensification) of the early 21 st century pandemic; and this current combining of dispositifs is only materially pertinent under capitalistic governmentality, as well as being collaterally efficient for such government. (Ayala-Colqui, 2020b: 389)

\footnotetext{
${ }^{1}$ Aprovecho el espacio de esta nota, después de conseguir la aceptación del artículo, para dedicar este modesto esfuerzo teórico a dos de mis familiares directos que fallecieron producto de la emergencia sanitaria en 2020 antes de que Perú, por razones estrictamente políticas y económicas, contara con tratamientos especializados y vacunas: Ramón Colqui Tovar, mi abuelo, y Ciro Colqui Rojas, mi tío. Ellos son, en este caso, los nombres propios de los sin voz, sin nombre, sin reconocimiento; quienes, como mero dato estadístico, fueron una anécdota más, abstracta e impersonal, de la crisis.
} 
Esta crítica a la clave hermenéutica biopolítica abreva, sin duda, de una segunda grilla de lectura que podríamos llamar "clave hermenéutica anticapitalista". Aquí sobresalen las intervenciones de Badiou (2020), Butler (2020), Lazzarato (2020) y Wallace, Liebman, Chaves \& Wallace (2020), las cuales ponen bajo los reflectores las dinámicas a la vez económicas y políticas que permitieron que una enfermedad viral se convirtiera en una crisis social sin precedentes: de un lado, las políticas económicas neoliberales propician un extractivismo industrial rapaz que destruye indiscriminadamente todo tipo ecosistemas dando cabida a la transmisión zoonótica de enfermedades; de otro, la privatización imperativa de todos los procesos sociales condicionan la disminución del gasto en la atención sanitaria y determinan no solo la carencia de implementos médicos necesarios, sino también su desigual distribución mundial.

Pues bien, nuestra presente intervención se sitúa a medio camino entre estas dos claves hermenéuticas retomando la noción de viropolítica -y también el concepto de "necropolítica" de Mbembe (2011) que explicaremos en su momento- a fin de pensar no la pandemia en sí misma, sino la relación entre las formas de gobierno en América Latina y los modos de gestión de la peste. Es decir, la pregunta de investigación que nos convoca es la siguiente: ¿cuál es el vínculo entre ciertas formas de gubernamentalidad latinoamericanas y las estrategias políticas de administración de las poblaciones durante los dos primeros años de la crisis pandémica? Para ello dividiremos el artículo en dos secciones. En la primera esclarecemos los tipos de gobierno existentes en Latinoamérica diferenciando entre neoliberalismo y, lo que convendremos en llamar, "liberfascismo". En la segunda analizaremos las particularidades viropolíticas y necropolíticas de la gestión de la pandemia según cada tipo de gubernamentalidad a partir de una referencia empírica a lo acontecido en Chile, Perú y Brasil; y, adicionalmente, incluiremos una referencia a la expansión de las tendencias ultraderechistas en América Latina durante el contexto de la pandemia y la posibilidad de que estas puedan generalizar la aplicación de medidas necropolíticas.

\section{Neoliberalismo, (neo)fascismo y nacimiento del liberfascismo antes de la pandemia de la Covid- 19}

En su curso de 1978, Foucault (2006) explicita el término "gubernamentalidad" (gouvernementalité) para entender la manera cómo funciona el poder en tanto "conducción de las conductas". Gobernar no es ejercer un poder soberano, sino inducir, alterar, manipular las conductas (Foucault, 1994b). Por ello, ciertos fenómenos políticos, como el neoliberalismo, no pueden ser comprendidos como meras ideologías, sino como prácticas de gobierno que intersecan, en su específica conducción, saberes y sujetos. En tal sentido, si se considera que en América Latina existe una predominancia del neoliberalismo, sobre todo en países como Chile o Perú, es menester comprender a este de un modo más comprehensivo y perfilar sus notas específicas en tanto gubernamentalidad.

La gubernamentalidad neoliberal, ante todo, se caracteriza por "gobernar para el mercado y no gobernar a causa del mercado" (Foucault, 2007: 154). Esto no excluye que haya diversas vertientes y orientaciones para materializar tal práctica de conducción de conductas. De hecho, se puede diferenciar tres corrientes neoliberales: la escuela alemana ordoliberal (Eucken, Röpke y Rüstow), la escuela austríaca (von Mises y Hayek) y la escuela de Chicago (Simons, Friedman, Buchanan y Baker). Son los alemanes quienes operan la inversión de la fórmula clásica del liberalismo (esto es, el Estado como posibilitador de un espacio para la libertad individual) en orden a dar paso a una lógica donde la libertad de mercado sea "principio organizador y regulador del Estado [...]. Para decirlo de otra manera, un Estado bajo la vigilancia del mercado más que un mercado bajo la vigilancia del Estado" (Foucault, 2007: 149). Con ello el concepto liberal del intercambio -asumido como un dato- es sustituido por el concepto neoliberal de la "competencia" - pensado como una normatividad, esto es, como una realidad a fabricar a partir de la intervención activa en la población y no directamente en el mercado (Foucault, 2007; Dardot \& Laval, 2013; Stiegler, 2019)-. Y son los americanos quienes abogan por una privatización total de los servicios públicos esenciales (educación, y salud, por ejemplo) a fin de promover la competencia privada en el mercado (Valdes, 1995; Fischer, 2009; Mirowski \& Plehwe, 2009; Audier, 2012). Postulan, además, 
que el trabajador ya no es un sujeto que produce valor, sino simplemente un "empresario de sí mismo", un "capital humano", dando lugar a un abordaje económico de todo fenómeno social (Boltanski \& Chiapello, 2002; Foucault, 2007; Dardot \& Laval, 2013; Paltrinieri, 2017) y dando cabida a prácticas emprendedoras, hedonistas y cínicas (Dardot \& Laval, 2013; Moruno; 2014; Sadin, 2018).

Ahora bien, se piensa que, con la defensa a la libertad, entendida exclusivamente como libertad económica individual y libertad de mercado - una libertad que no cesa de ser artificial y condicionada por factores económicos (Foucault, 2007; Dardot \& Laval, 2013; Maruy, 2019)-, el neoliberalismo se encontraría en las antípodas del totalitarismo y de la violencia. No obstante, ello es falaz por dos razones. Por un lado, desde un punto de vista teórico, en el corazón mismo del (neo)liberalismo se encuentran procedimientos de coacción y coerción, dado que el control no solo se concibe como el contrapeso de las libertades, sino ante todo como "su principal motor" (Foucault, 2007: 89). Por otro lado, en la práctica, el neoliberalismo ha avalado golpes de Estado en América Latina (Brown, 2016), así como regímenes militarizados y represivos (Hinkelammert, 1984). Y en paralelo se ha generalizado una sujeción de las conductas por medio del endeudamiento (Lazzarato 2013 y 2015) y las finanzas (Marazzi, 2014), tanto cuanto por medio de un sufrimiento psíquico sin precedentes (Berardi, 2003) y una creciente “acumulación por desposesión" (Harvey, 2004) que redundan en el cariz violento (Sacchi, 2017), máxime bélico (Alliez \& Lazzarato, 2016), de la práctica neoliberal.

Aún más, luego de la crisis financiera en 2007 múltiples escritores han descrito el recrudecimiento de la violencia neoliberal hablándose así de un "momento fascista" del neoliberalismo (Fassin, 2018; PavónCuellar, 2020) o de una versión "punitiva" (Davies, 2016) y "autoritaria" (Chamayou, 2018; Ryan, 2019) del mismo que acentuaría su intrínseca violencia política (Alliez \& Lazzarato, 2016; Dardot \& Laval, 2017; Saidel, 2020), cuya expresión modélica mundial no sería sino Trump.

Sin embargo, aquí no debe confundirse neoliberalismo y fascismo, puesto que en tal indistinción no solo se incurre en una imprecisión conceptual, sino también en un anacronismo generalizante. Ambos modos de gobierno son fenómenos históricos precisos y acotados en el tiempo; poseen, igualmente, características peculiares y distintivas. El fascismo es, pues, una experiencia histórica concreta, antes que un universal abstracto, el cual se define por sus componentes nacionalistas, estadolátricos, xenófobos, conservadores, antiintelectualistas, militaristas, antiliberales (Poulantzas, 1976; Bobbio, 2006), antimodernos, demagógicos, propagandísticos y totalitarios (Paxton, 2019). Poulantzas (1976) y Borón (2017) puntualizan que el fascismo, pese a sus críticas ambiguas al liberalismo, es un "régimen de Estado capitalista de excepción" que responde, a la vez, a una crisis económica, política e ideológica, a saber: la crisis imperialista del capitalismo posterior a la primera guerra mundial.

Por consiguiente, es impreciso denominar a las experiencias históricas de comienzos del s. XXI como neoliberalismo "fascista". De ahí que algunos autores hayan propuesto el término "neofascismo" para pensar en términos más amplios el auge de las nuevas extremas derechas (Casals, 2003; Antón-Mellón \& Hernández-Carr, 2016; Sztulwark, 2019; Guamán, Aragoneses \& Martín, 2019)² . En efecto, a partir de la constatación de una diferencia entre dos tipos de partidos de ultraderecha, unos llamados "extrema derecha tradicional" (que tendría un vínculo pasadista con la simbología fascista originaria) y otros denominados "extrema derecha postindustrial" o "nueva extrema derecha" -una alternative right- (que renovaría sus contenidos y se desmarcaría de unos orígenes totalitarios y antidemocráticos) (Ignazi,

\footnotetext{
${ }^{2}$ Conviene comentar otras denominaciones sobre los nuevos movimientos de derecha y apuntar las razones por las cuales rechazamos su uso. Badiou (2019) emplea, por ejemplo, el término "fascismo democrático" a partir de un análisis de la elección de Trump en 2016. Consideramos doble el error del filósofo francés: por un lado, en la categoría mencionada incluye a actores no estrictamente homogéneos como Berlusconi, Sarkozy y Le Pen y, por otro lado, su caracterización no se basa en los caracteres de los movimientos políticos, sino en los rasgos psicológicos del representante político, como si bastara que un presidente sea chauvinista o racista para que, ipso facto, su gobernanza se convierta en fascista. Giroux (2018) plantea, a su turno, el vocablo "fascismo neoliberal" para describir también el gobierno de Trump. El problema con esta conceptualización es que el escritor canadiense asume que aquel término representaría una nueva fase del neoliberalismo donde el fascismo, entendido erróneamente como un concepto ahistórico, vendría a mixturarse con él. Así se considera que hay una suerte de "fascismo milenario" (millenial fascism) que existía ya antes de Trump -en la violación sistemática de derechos humanos y la reducción de toda actividad humana al mercado- y que, durante el gobierno del mencionado presidente, vendría a exacerbarse. No obstante, como bien lo apuntan los otros investigadores citados, el neofascismo no se reduce simplemente a una inflexión del neoliberalismo, sino a una gubernamentalidad propia y autónoma.
} 
2003; Mudde, 2007), se ha elaborado la categoría neofascista para describir a estos últimos. Así, los rasgos esenciales del neofascismo serían el nacionalismo -o el "nativismo": solo deben habitar los nativos en los Estados-nación (Mude, 2007)-, el populismo y el autoritarismo (Casals, 2003; AntónMellón \& Hernández-Carr, 2016). Sus ejemplos elocuentes serían los partidos Frente Nacional (Francia), Liga Norte (Italia) y Partido de la Libertad (Austria).

Mas, ¿realmente hay un neofascismo en América Latina? ¿Son Bolsonaro y los grupos de extrema derecha surgidos en la región neofascistas? ¿O por el contrario estamos ante un acontecimiento inopinado que escapa a las categorías al uso? ¿No hemos ido muy rápido al caracterizar a nuevas realidades con la anexión veloz del prefijo "neo" o incluso "pos" ? ¿Realmente estos modos de gubernamentalidad rechazan el neoliberalismo y, en general, la economía de mercado? ¿No será que, por el contrario, la apologizan, la reivindican, la ensalzan? ¿Se trata, entonces, de una indistinción entre neoliberalismo y fascismo o, más bien, de un nuevo fenómeno político que no se puede reducir unilateralmente a estos acontecimientos históricos?

Veamos las cosas con un poco más de detenimiento. Bolsonaro no es simplemente un neofascista: su autoritarismo, populismo y conservadurismo no deben hacernos perder de vista su devoción por el "libre" mercado, la privatización y la mercantilización de toda la realidad social (Kalil, 2020; Fonseca \& da Silva, 2020; Stewart et al., 2021); un fervor que lo llevó a decir en plena pandemia de la Covid-19 y con una tasa altísima de muertos: "there's no reason not to let these people work. After all, if the virus kills in some cases, hunger also kills" (Reuters, 2020). Denominarlos neofascistas podría llevar al error de suprimir toda referencia al totalitarismo de mercado presupuesto. El presidente brasileño no es, además, asimilable al Frente Nacional (Francia), la Liga Norte (Italia) o el Partido de la Libertad (Austria). Y, en términos más amplios, la "extrema derecha postindustrial" o la "nueva extrema derecha" (Ignazi, 2003; Mudde, 2007) en América Latina -cuyos representantes políticos además de Bolsonaro son, de momento, Aliaga en Perú, Kast en Chile, Milei en Argentina y los demás grupos de "libertarios"no solo remiten a los elementos nacionalistas, populistas y autoritarios propios del neofascismo europeo. Ellos poseen, de manera fundamental y distintiva, un culto irrefrenable y paranoico de la libertad de mercado y la propiedad privada. Inclusive con poses de indignación y rebeldía, y a través del uso intensivo de redes sociales y plataformas virtuales (Stefanoni, 2021), difunden con desparpajo su fe en el mercado y su fobia a toda propuesta de justicia e igualdad, esto es, a lo que denominan, sin ningún cariz crítico o reflexivo, "comunismo" o "marxismo cultural".

Para nombrar a esta nueva experiencia histórica de gubernamentalidad de comienzos del s. XXI en América Latina que no se puede reducir simplemente al neoliberalismo - sea en su período combativo, normativo o punitivo según la taxonomía bastante eurocéntrica de Davies (2016) - ni tampoco al neofascismo -cuyas expresiones más logradas se pueden agrupar en la Nouvelle droite europea-, sino que por el contrario los excede y los desborda, consideramos pertinente forjar el término "liberfascismo". En efecto, si a nivel de la producción de la subjetividad y los modos de gubernamentalidad el neoliberalismo se caracteriza por la asunción de la competencia y el empresario de sí, además del hedonismo, el emprendedurismo y el cinismo; y si el neofascismo se ultima por la adopción del nacionalismo, el populismo y el autoritarismo; el liberfascismo no se define sino por la postulación del mercantilismo y el defensor-de-sí, además del segregacionismo, el conservadurismo y el conspiracionismo. El mercantilismo significa aquí una defensa apologética de la propiedad privada, el libre mercado y el modo de producción capitalista, modo en el cual, no obstante, los liberfascistas no poseen una posición dominante, toda vez que son, por lo general, pequeñoburgueses arribistas; el defensor de sí mienta la defensa reactiva, por medio de una propensión a actividades abiertamente violentas, máxime armadas (a partir de la conformación de pequeñas milicias populares), de un sí mismo asumido como propiedad privada contra los embates de un imaginario progresismo o un cierto establishment político que pondría en peligro dicha posesión personal; el segregacionismo remite, como consecuencia de lo anterior, al emplazamiento de una identidad excluyente y bélica que se resuelve en

\footnotetext{
${ }^{3}$ Traverso (2016) avanza aún más velozmente y propone el concepto "posfascismo". Ya Sztulwark (2019) y Figueroa \& Moreno (2020) han cuestionado que una nominación tal corre el riesgo de considerar como cancelada la herencia totalitaria y violentista del fascismo histórico.
} 
una antiigualitarismo militante y generalizante, cuyas declinaciones variables pueden ser la xenofobia, el racismo, el machismo y la homofobia; el conservadurismo indica la reivindicación de unos valores que se juzgan ingenuamente ácronos y naturales (la heterosexualidad, la familia, la identidad nacional, la sumisión femenina, las jerarquías sociales); el conspiracionismo, en fin, hace referencia a la admisión de la posverdad como criterio de verdad, de modo que sus fragmentos falaces de presunciones económicas neoliberales son suplementados con amplios fake news y teorías de la conspiración de todo calibre.

Como bien lo señalan Deleuze y Guattari (1985) cuando tematizan el fascismo, este no se trata únicamente de una cuestión de prácticas e instituciones políticas: expresa, ante todo, un momento de captura del deseo que produce subjetividades segregativas, totalitarias y biunívocas. Por consiguiente, también el liberfascismo, en tanto subjetividad -conducción de sí mismo-, es un modo de modelamiento del deseo que remite a la clásica cuestión de la "servidumbre voluntaria", la cual se expresa, en la hechura liberfascista, en la defensa de la propiedad de sí (ellos han interiorizado tanto la dominación capitalista que la expresan como el más alto grado de liberación y la posesión de un pequeña propiedad, en un sistema que empero la destruye para dar paso a la gran acumulación del capital, como un logro insuperable e inalienable). Y, en tanto gubernamentalidad -conducción de la conducta de los otros-, es una práctica segregacionista que violenta, por medio del conservadurismo y el conspiracionismo, toda forma de vida divergente (el liberfascista como milicia que pasa a la acción, en tanto defensor de sí, contra todo aquel que ponga en cuestión sus certezas y ansiedades). Con estos elementos quedan delimitados, pues, el devenir liberfascista de la subjetividad y la estratificación liberfascista de la gubernamentalidad.

Sin duda hay elementos que el liberfascismo comparte tanto con el neofascismo occidental como con el neoliberalismo, a saber: respectivamente, sus caracteres nacionalistas y autoritarios, sus rasgos normativos y promercado. No obstante, el liberfascista tiene la singularidad de que no se reconoce de buenas a primeras como fascista o, mejor dicho, no considera como elemento fundante de su identidad el nacionalismo populista y punitivo, sino que, por el contrario, es la libertad individual y económica el fundamento de su práctica política y el horizonte desde la cual resulta inteligible las experiencias segregativas, defensoras, conspirativas y conservadoras. Mientras que en el neofascismo el nativismo es el soporte tanto del autoritarismo como del populismo; en el liberfascismo es la libertad abstracta, idealizada y mercantil la que vertebra las estructuras de su significación política. Por ello, sería un error identificar neofascismo y liberfascismo. El liberfascismo, asimismo, difiere del neoliberalismo, en la medida que de la premisa de la libertad obtienen conclusiones diferentes. En efecto, en la gubernamentalidad neoliberal, de la libertad individual se extrae que toda interacción social se encuentra mediada por la competencia a partir de un sujeto asumido como capital humano; mientras que, en la gubernamentalidad liberfascista, de la libertad personal se infiere que toda relación social está vehiculizada por la segregación del otro no liberfascista a partir de un sujeto considerado como defensor de su propiedad de sí en tanto creador soberano y privado de toda riqueza social. Por ello, no es admisible postular que el liberfascismo sería una fase o un momento interno del gobierno neoliberal, por más que ambos remitan al modo de producción capitalista.

Ahora, el liberfascismo históricamente ha surgido como respuesta a la crisis del neoliberalismo y la interseccionalidad de críticas al capital ${ }^{4}$. Si históricamente el fascismo fue la válvula de escape de la crisis del gobierno capitalista posterior a la primera guerra mundial, el liberfascismo responde a la devastación del modelo neoliberal y la crítica creciente de movimientos interseccionales. Bolsonaro, no en tanto persona individual sino en tanto significante que agrupa una colectividad social, simboliza el primer hito del liberfascismo en América Latina, en la medida que, a partir de una crítica retórica al establishment neoliberal y una oposición visceral a las luchas interseccionales, pone en escena una performance liberfascista y afirma unos rasgos segregativos, violentistas, ultraconservadores $\mathrm{y}$ conspirativos, así como mercantiles y procapitalistas.

\footnotetext{
${ }^{4}$ Con este último término hacemos referencia a la interseccionalidad, tal como lo conceptualiza Hill Collins y Bilge (2019), como una praxis crítica, y no solo un enfoque analítico, que interconecta luchas de clase, género, ecología, raza.
} 
¿Qué relación tiene la forma de gobierno y la forma de subjetivación neoliberal y liberfascista con la viropolítica, máxime con la necropolítica, en la gestión de la pandemia?

\section{Viropolítica y necropolítica en las gubernamentalidades neoliberales y liberfascistas en América Latina durante la pandemia de la Covid-19}

Resulta correcto, al menos parcialmente, considerar que el gobierno de las colectividades durante la crisis sanitaria obedece a un esquema biopolítico (Agamben, 2020a, 2020b y 2020d; Hillani, 2021; Kaya, 2021; Manichkin, 2021). Recordemos que el término biopolítica fue introducido por Foucault (2000; 2002) para pensar una tecnología de poder distinta a la anatomopolítica. Mientras esta se centra en la disciplina del cuerpo humano a efectos de hacerlo dócil y útil; la última toma como objeto la vida de la población en orden a regularla y normalizarla (Foucault, 2006). Cada uno de estas trabaja con un dispositivo (dispositif) diferente -si entendemos por esta noción una red de componentes discursivos y no discursivos que responden a una urgencia política (Foucault, 1994a)-: dispositivos disciplinarios y dispositivos de seguridad (Foucault, 2006). A este respecto, la gestión de la pandemia ha implicado, naturalmente, una regulación de la vida humana de la población, toda vez que se trata de modificar la curva de contagios a unas condiciones normales donde los niveles de enfermedad y mortalidad se encuentren en límites estables y seguros para el óptimo funcionamiento de la sociedad, funcionamiento que no coincide sino, por supuesto, con la valorización del capital. Pero, además de dispositivos biopolíticos, la pandemia trajo consigo medidas anatomopolíticas y legales. Por un lado, el encerramiento coercitivo y la vigilancia punitiva han modelado sobremanera el disciplinamiento corporal de los sujetos, sea en los hogares para el caso de los que poseen una vivienda, sea a la intemperie para los desposeídos. Por otro lado, la proliferación de ordenanzas, normas, decretos y leyes que modifican la tesitura jurídica de la sociedad han servido para reforzar a los dispositivos de disciplina y seguridad descritos.

Mas la pandemia también supuso la intervención de otro dispositivo no previsto por Foucault y, en cierto modo, intuido por Deleuze (2006) cuando hablaba de las sociedades de control. Nos referimos a los dispositivos que podemos denominar "algorítmicos", esto es, las tecnologías que tienen como objetivo la predicción de la conducta humana, así como su programación o "formateo". Estos dispositivos electrónicos realizan, a partir del recurso a la información en tanto data de los usuarios, un modelamiento, pronóstico y encauzamiento de la actividad de los sujetos (Pasquinelli, 2014; Sadin, 2015; Rodríguez, 2019; Constante, 2020) y en el caso de la peste tienen como objetivo, en el variable desarrollo tecnológico de cada sociedad, la geolocalización en tiempo real, el pronóstico virtual, el control digital de actuales y potenciales contagiados.

Por ello, pensar la pandemia en términos exclusivamente biopolíticos, como Agamben y compañía, resulta estrecho y sesgado. De ahí nuestra recurrencia al ya citado término "viropolítica" que, creemos, condensa la articulación de dispositivos legales, disciplinarios, "securitarios" y algorítmicos, los cuales, solo bajo ciertos supuestos que a continuación explicitaremos, persiguen el mantenimiento de la población a fin de conservar el ciclo económico del capital. Sin población normada resulta imposible proseguir con la cadena de producción, consumo, endeudamiento y financiamiento que requiere el gobierno neoliberal (Ayala-Colqui, 2020b). Pues, bajo el neoliberalismo, todo fenómeno social, incluyendo los acontecimientos relativos a la salud pública, forman parte de una matriz económica que evalúa toda la realidad en términos de rentabilidad e incremento de capital (Foucault, 2007; Dardot \& Laval, 2013 y 2017; Brown, 2016).

Ahora bien, la primera hipótesis que propondremos aquí es la siguiente: la viropolítica fue la forma generalizada de manejo de la pandemia en América Latina, especialmente la del neoliberalismo; la necropolítica, por contraste, fue el modo de gestión distintiva y esencial del liberfascismo.

Consideremos, primero, tres países de América Latina para analizar la actualidad de la viropolítica: uno de ellos con una momentánea y relativa política socialdemócrata; los otros dos con un decidido y explícito carácter neoliberal. Nos referimos, respectivamente, a Argentina, Chile y Perú. 
En caso de la Argentina, el gobierno de Fernández supuso un revés a algunas de las políticas neoliberales efectuadas previamente por Macri, las cuales hunden sus raíces en el nefasto período dictatorial de 1976. Por eso, las medidas adoptadas persiguieron no tanto un refuerzo de la economía de mercado, sino la contención social y económica de los trabajadores. Además de la disciplina anatomopolítica, la regulación biopolítica y el control algorítmico -suspensión de actividades masivas, controles fronterizos, aislamiento social preventivo y obligatorio (ASPO) (Boletín Oficial de la República de Argentina, 2020)-, hubo un fuerte énfasis en los programas de seguridad y protección social, donde destaca el Plan Básico Universal y el Programa de Recuperación Productiva (REPRO), siendo este último un fondo económico destinado directamente a los trabajadores, y el establecimiento de precios máximos en los productos de primera necesidad (Ernst \& López, 2020). Vemos que aquí "la viropolítica" no regula la vida de los trabajadores para estabilizarlos estadísticamente y hacerlos funcionales a la valorización del capital, sino que, en muchos casos, afirma la vida de los trabajadores antes que el interés de las empresas.

Así como Esposito (2006) separa la biopolítica negativa de la biopolítica positiva, la cual puede ser leída, mutatis mutandis, como la distinción realizada por Negri (2004) entre biopoder, en tanto conjunto de dispositivos que hace de la vida un objeto para el beneficio del capital, y biopolítica, en tanto modo de resistencia que tiene como meta la afirmación de la potencia vital; análogamente, hay una diferencia entre una viropolítica negativa, cuyo manejo de la pandemia enfatiza el beneficio del gran capital y una viropolítica afirmativa que se propone expresar la resistencia de las colectividades sociales.

Por consiguiente, en la Argentina se puede apreciar la presencia de una viropolítica positiva que, allende los dispositivos gubernamentales de conducción de los sujetos, realiza una cierta resistencia contra la lógica del capital.

En el caso de Chile -cuya Constitución de 1980 considera la salud dentro de la tópica de la elección del libre mercado asumiendo, sin más, que todas las personas poseen las mismas condiciones económicas: "Cada persona tendrá el derecho a elegir el sistema de salud al que desee acogerse, sea éste estatal o privado" (Biblioteca del Congreso Nacional de Chile, 2021, Capítulo III, artículo 9)- nos encontramos con un panorama distinto, esto es, un neoliberalismo galopante. Así, la declaración de alerta sanitaria y, más aún, la declaratoria de un "estado de excepción constitucional" dio el horizonte legal desde el cual implementar dispositivos disciplinarios, biopolíticos y algorítmicos no solo para regular la conducta de los sujetos en las cuarentenas y controles dirigidos (Diario Oficial de Chile, 2020a, 2020b, 2020c), sino, ante todo, para conducirlos económicamente al buen cauce del neoliberalismo al institucionalizar los despidos, legitimar la suspensión de ingresos durante las licencias médicas y, por si fuera poco, endeudar a los solicitantes de bonos sociales bajo el eufemismo insólito de "Préstamo solidario" (Diario Oficial de Chile, 2020d, 2020e). Al ser implementados estos dispositivos desde un horizonte neoliberal, ellos se encuentran supeditados "a criterios económicos, cálculos de utilidad de costo y beneficio, que tienen por finalidad ser aplicados en ámbitos no económicos, que hace del ciudadano ya no un sujeto de derechos sino de [...] capital humano" (Silva-Escobar, 2021: 439). Por consiguiente, en Chile, bajo el neoliberalismo, la gestión de la pandemia no es sino una viropolítica negativa.

En el caso de Perú - país donde la Constitución neoliberal de 1993 sigue aún vigente y en la cual el "derecho a la salud" no se considera un derecho fundamental, sino un mero derecho "social y económico" (Presidencia de la República del Perú, 2018), es decir, se prejuzga también que todo ciudadano podrá sin más, por mero abracadabra jurídico, disponer materialmente de ella-, se declaró, a nivel de dispositivo legal, el primer estado de "Emergencia Sanitaria" a causa del avance de la pandemia. Se impuso, asimismo, un "Estado de Emergencia Nacional" que normativizó, con dispositivos disciplinarios, biopolíticos e incipientemente algorítmicos, "el aislamiento social obligatorio (cuarentena)" (El Peruano, 2020a; Velázquez Castro, 2020). No hubo, por contraste, ninguna medida destinada a modificar el estatuto jurídico de la salud para que pase de ser un servicio social y económico a un derecho esencial libre y gratuito, sino tan solo una serie de disposiciones que tenían como objetivo regularizar la situación pandémica a efectos de no devastar la circulación neoliberal de la economía. Pasada la pandemia, la salud tendría que volver a ser un servicio precariamente brindado por el Estado y a una mercancía de precios exorbitantes vendida por el mercado. Y, por si eso no bastare, en este país 
aconteció el llamado "Vacuganate" (Mayta-Tristán \& Aparco, 2021), a saber: la élite económico-política decidió vacunarse a espaldas de la población antes de que existiera una política de distribución pública de las vacunas y en medio de cifras deplorables de enfermos y contagiados. Todo es válido, en tanto recurso e "inversión", para consolidar la vida como capital humano a expensas de los demás. En consecuencia, en Perú se trata de una viropolítica negativa que no persigue como objetivo más que la recuperación económica del gran capital.

En estos dos últimos países la temporal adopción de medidas keynesianas no niega el carácter neoliberal de sus gobiernos - precipitadamente otros piensan que sí (Saad-Filho, 2020)-. La intervención del Estado en la economía no constituye la antítesis del libre mercado sino su sostén temporal, su prolongación necesaria, su condición de posibilidad. Tal como sucedió en la crisis financiera de 2007: es el Estado el que se muestra como una peripecia de la gubernamentalidad neoliberal al salvar a las empresas endeudando para ello a los ciudadanos. Los bonos y subvenciones a las personas en estos países no tenían como destino el bienestar de los ciudadanos, sino la continuidad del consumo para el beneficio de las empresas y la continuidad de la fuerza laboral para la productividad capitalista. Aún más, el carácter neoliberal de los programas sociales resulta plenamente ostensible en la coyuntura peruana. En efecto, se implementó en el país andino un programa denominado "Reactiva Perú", destinado a inyectar liquidez para la continuidad de la producción empresarial, tasado en 60 millones de soles (aproximadamente más de 15 millones de dólares) (El Peruano, 2020b; 2020c), el cual fue a parar a manos del gran empresariado. Este, por si fuera poco, se tomó la ligereza de despedir a sus trabajadores bajo la figura eufemística de la "suspensión perfecta", normativa que el Ministerio de Economía promulgó expeditivamente (El Peruano, 2020d). Con ello se refuerza lo que ya señalaba Foucault (2007) y lo que reiteran Dardot y Laval (2003): el neoliberalismo interviene activamente $-\mathrm{y}$ no solo en los Estados explícitamente capturados por la gran burguesía (Durand, 2019)- para producir artificialmente el mercado. Por otro lado, más allá de este soterrado y permanente intervencionismo, el mercado "libre" no es de ningún modo la instancia donde todos los problemas son solucionados, pues su desregulación no provocó sino en la pandemia escasez de implementos médicos, disminución del presupuesto de salud pública y una forzosa distribución desigual de tratamientos y vacunas (Badiou, 2020; Butler, 2020; Daher-Nashif, 2022; Lazzarato, 2020; Wallace, Liebman, Chaves \& Wallace, 2020). A fin de cuentas, las medidas viropolíticas no sirvieron más que para evitar el quiebre de la gubernamentalidad neoliberal impidiendo que esta se quede sin una cantidad normal y controlada de población que produzca, consuma y se endeude.

Pero, ¿qué pasa en el caso del Brasil de Bolsonaro, país donde funge, como se ha explicado, una gubernamentalidad liberfascista?

El 24 de marzo de 2020, a inicios de la pandemia, el gobernante brasileño realizó un mensaje público donde no solo calificó a la enfermedad causada por el nuevo virus como una "gripezinha ou um resfriadinho", sino que planteó una dicotomía entre la crisis económica o el caos social (Cavalcante, 2021). Posteriormente, el gobierno lanzó la campaña "O Brasil não pode parar" (Pele \& Wilson, 2020) donde la salvaguarda de la economía no se basó en la regulación de la vida de los sujetos, sino en la posibilidad abierta, máxime necesaria, de su muerte sin discreción. La disyuntiva se acentuó: o la libertad económica liberfascista o la vida de la población; elegir la primera implica, forzosamente, optar por la muerte o el sacrificio de la segunda. Solo por la mediación de estas muertes, el defensor de la propiedad de sí liberfascista puede realizar su devoción mercantil y, a la par, una segregación violenta de los que no son como ellos, libres y autodefensores, capitalistas y ultraconservadores. Aunque retóricamente se oponen a las cuarentenas, son, de facto, los únicos que por su condición de clase pueden sobrellevarla:

Assim, a possibilidade de quarentena das classes privilegiadas existiria somente graças à impossibilidade de que as classes menos favorecidas adotassem a mesma postura, continuando a trabalhar para a disponibilização de bens e serviços essenciais. De outro modo, algumas vidas podem ser protegidas pela assunção do risco pelas classes trabalhadoras, que não teriam o "privilégio" de fazer quarentena (Pele \& Wilson, 2020: 161) 
Sin embargo, ignorando deliberadamente este factum, los liberfascistas abogaron por una supresión de las medidas restrictivas:

Empresários de vários setores que compunham a base bolsonarista passaram a denunciar igualmente o "desequilíbrio" das medidas que causariam desemprego e o sofrimento (e até mesmo o suicídio) de milhões de pessoas em comparação com a morte de "alguns milhares" de infectados (Cavalcante, 2021: 9)

De este modo el liberfascismo puede realizar dos de sus características en un mismo movimiento: salvar el mercado y, a la vez, producir el segregacionismo como tal. La consecuencia tangible de ello no ha sido sino, en efecto, la muerte masiva, no de los liberfascistas pequeñoburgueses o burgueses, por supuesto, sino de negros e indígenas desposeídos: "proportionally more indigenous and black people die from COVID-19 than the white population" (Lucas et al., 2021: 444).

Esta negativa frente a la evidencia material entronca con otro rasgo fundamental del liberfascismo: la propensión a la conspiración o, si se quiere, la instauración de la posverdad como gnoseología política. Bolsonaro, en tanto portavoz de la gubernamentalidad liberfascista, se dedicó incesantemente, tanto a nivel pragmático como a nivel discursivo (en una multiplicidad de plataformas virtuales y en pronunciamientos oficiales), a difundir una serie de bulos sobre la pandemia: "Misinformation spread on President Bolsonaro's official social-media profiles includes his promotion of ineffective medications, his statements against social distancing, and his encouragement of agglomerations without the use of masks" (Lucas et al., 2021: 441). Es importante señalar que aquí el conspiracionismo y el negacionismo no son productos de la ignorancia, que bien podría ser cancelados por una intromisión del saber científico o razonable: forma parte, por el contrario, del modo de gobierno en calidad de "veridicción" (Ayala-Colqui, 2020a), esto es, en tanto conjunto discursivo que, allende su cualidad veritativa, tiene por objeto modificar las acciones de los sujetos.

No existió en el liberfascismo una amalgama de dispositivos disciplinarios, securitarios o algorítmicos para mantener en condiciones normales y controladas a la población. No hubo viropolítica en Brasil, ni positiva ni negativa. Aconteció, por contraste, una "necropolítica". Por este término hay que entender una estrategia de poder que implica la producción deliberada de la muerte como medio esencial de realización de una determinada gubernamentalidad. Tal y como lo dice Mbembe (2011):

he utilizado las nociones de política de la muerte [necropolítica] y de poder de la muerte [necropoder], para reflejar los diversos medios por los cuales, en nuestro mundo contemporáneo, las armas se despliegan con el objetivo de una destrucción máxima de las personas y de la creación de mundos de muerte (p. 75)

En el caso de Brasil, la necropolítica fue la estrategia propia de la gubernamentalidad liberfascista y sus armas fueron la desinformación, la apoteosis del mercado y el segregacionismo. Brasil, bajo el patrocinio liberfascista, confirmó con creces la política de la muerte y el control de la mortalidad, pues hizo "del asesinato de su enemigo su objetivo primero y absoluto" (Mbembe, 2011: 20). Un genocidio, claro está, de los otros no liberfascistas y enemigos por excelencia, esto es, los no pequeñoburgueses y burgueses, los que no defienden el mercado, los que no siguen la posverdad, los que son segregados por poner en cuestión, con su sola existencia, la égida de valores conservadores del defensor de la propiedad de sí. Se trató, en suma, de una necropolítica de la "gestão da morte de forma organizada, planificada, tecnológica" (Dornelles, 2020: 99).

Mientras que en el caso de la viropolítica negativa se trata de un mantenimiento interesado de la población, en la necropolítica se trata de un exterminio deliberado de la misma. Es decir, mientras el neoliberalismo requiere de hacer vivir a la población para un fin económico, dejando morir a los que caen fuera de la normalidad estadística y el control económico y epidemiológico; el liberfascismo necesita hacer morir a la población en orden a mantener la propiedad intrínseca y solipsista del defensor de sí, dejando vivir solo a los que, por su condición económica, entran o pueden entrar en el círculo del mercantilismo desenfrenado y el segregacionismo esforzado. Y, por ello, la necropolítica siempre es, necesariamente, negativa, mientras que la viropolítica puede mantener cierta ambivalencia dependiendo 
de sus fines y usos. O mejor dicho: la positividad de la necropolítica no reside sino en la negación de la vida de los otros.

Y es aquí donde queremos señalar, asaz brevemente y para concluir, nuestra segunda y última hipótesis: la pandemia creó las condiciones para expandir el liberfascismo latinoamericano en los lugares donde formalmente aún no toma las instituciones políticas.

Es conocido que Foucault $(2002 ; 2018)$ plantea la resistencia (Castro Orellana, 2017; Durán Rojas \& Torres Apablaza, 2020) y posteriormente la crítica (Ríos, 2019; Ayala-Colqui, 2020a), en tanto "contraconducta" (contre-conduite), como un modo de oponerse a las relaciones de poder con sus respectivos dispositivos anatomopolíticos o biopolíticos $-\mathrm{y}$, añadimos nosotros, viropolíticos o necropolíticos-. Generalmente, la resistencia se ha entendido en un sentido revolucionario y/o interseccional, esto es, ligados a luchas de clase, género, raza, ecología, etc. No obstante, es menester decir que hay también resistencias reaccionarias y fascistas.

En efecto, son precisamente los liberfascistas quienes hacen gala de un sentido reactivo excepcional. El título de uno de los grupos extremistas en Perú no da lugar a equívocos: se conciben a sí mismos como "La Resistencia" (Salazar, 2021), es decir, asumen que resisten contra los embates conspirativos de los grupos interseccionales. Esto que puede parecer atípico es, en realidad, orgánico y correlativo a la gubernamentalidad liberfascista. Recordemos que ellos plantean el defensor de sí como el paradigma subjetivo. Por esa razón resistir no es para ellos un acto meramente negativo: es, de hecho, la afirmación, por exceso, de la premisa del defensor de sí segregativo, mercantil y conservador. Bajo tales coordenadas resulta inteligible la oposición férrea a las medidas de contención social, asumidas como contrarias al liberfascismo. Milei, abanderado de esta defensa, señaló categóricamente contra su país: "Este Gobierno impuso una cuarentena cavernícola y liberticida [sic]" (La Nación, 2020).

Han sido, pues, los dispositivos viropolíticos los que han permitido dotar de concreción este talante reactivo liberfascista y extenderlo como una peste subterránea. Frente a la conducción de las conductas viropolíticas en el uso del barbijo, el distanciamiento social, la reclusión y la cuarentena, el liberfascista ha asumido absolutamente una contraconducta. Pero se trata, como no podría ser de otra manera, de una contraconducta necropolítica, cuyo efecto será la muerte no exactamente de ellos quienes, de uno u otro modo en tanto (pequeño)burgueses, pueden gestionarse cierto cuidado médico, sino de los desposeídos, esto es, el otro no liberfascista que no puede ni siquiera llegar a afirmar la propiedad privada de sí. (Esto da, por lo demás, la indicación que la cuestión de la resistencia no debe tomar solo el epifenómeno del poder, sea biopolítico o lo que sea, sino la interrelación de dominaciones sobre la clase, la raza, el género). Así la gestión neoliberal de la pandemia ha permitido sumar adeptos contra las medidas viropolíticas impuestas a fin de reforzar su militancia y organizarse en redes sociales y en movilizaciones urbanas. En Argentina, Chile y Perú si bien no se institucionalizó una política pública necropolítica, sí se difundió por el cuerpo social la contraconducta necrofílica del liberfascismo, merced al contexto de la pandemia.

\section{A modo de conclusión}

Nos gustaría finalizar este artículo recordando la intuición fundamental de Deleuze y Guattari (1985): el fascismo nos habita; no es que los fascistas estén allá y nosotros aquí: devenir liberfascista es una cuestión de coyuntura y requiere para evitarlo un devenir menor que se distancie explícitamente del gobierno de capital (Deleuze \& Guattari, 1988). En Perú, el candidato ultraconservador, si bien no llegó a la presidencia, quedó en segundo lugar en la capital, Lima, ganando en los distritos más pudientes de la ciudad con casi la tercera parte de los votos (Cabral, 2021). En Argentina, Milei obtuvo cinco escaños convirtiéndose en la tercera fuerza política de la cámara baja (Centenera, 2021). En Chile, en fin, Kast asoma con fuerza, pese a solo cumplirse un aniversario del estallido social, y -al momento de redactar este texto, finales del 2021- se ubica en segundo lugar entre las preferencias presidenciales (Karmy, 2021; Montes, 2021). No es posible descartar que, así como hubo una década progresista en América Latina, pueda existir una década liberfascista en la región donde los nefastos sucesos acaecidos en Brasil 
no sean sino, en comparativa, un pasado remoto, a la vez negado en su realidad y celebrado propagandísticamente por su magno talante conservador, segregacionista y capitalista. Más allá de la cifra infausta de miles de muertos, está la posibilidad de que la verdadera tragedia de la pandemia sea la herencia liberfascista en expansión. Ante esto, la viropolítica y la necropolítica podrían ser tan solo un efímero y superficial avatar. Habrá que construir entonces no solo otros conceptos, sino también otras formas de ofensiva y resistencia.

\section{Referencias}

Agamben, G. (1998). Homo Sacer. El poder soberano y la nuda vida. Pre-textos. Valencia.

Agamben, G. (2003). Estado de excepción. Homo Sacer, II, I. Adriana Hidalgo. Buenos Aires.

Agamben. G. (2008). El reino y la gloria. Adriana Hidalgo. Buenos Aires.

Agamben, G. (2020a). L'invenzione di un'epidemia. Quodlibet. Recuperado de: https://www.quodlibet.it/giorgio-agamben-l-invenzione-di-un-epidemia [Consultado el 6 de noviembre de 2021].

Agamben, G. (2020b). Chiarimenti. Quodlibet. Recuperado de: https://www.quodlibet.it/giorgioagamben-chiarimenti [Consultado el 6 de noviembre de 2021].

Agamben, G. (2020c). Sul vero e sul falso. Quodlibet. Recuperado de: https://www.quodlibet.it/giorgioagamben-sul-vero-e-sul-falso [Consultado el 6 de noviembre de 2021].

Agamben, G. (2020d). Biosicurezza e politica. Quodlibet. Recuperado de: https://www.quodlibet.it/giorgio-agamben-biosicurezza [Consultado el 6 de noviembre de 2021].

Alliez, É. \& Lazzarato, M. (2016). Guerres et Capital. Amsterdam. Paris.

Antón-Mellón, J. \& Hernández-Carr, A. (2016). El crecimiento electoral de la derecha radical populista en Europa: parámetros ideológicos y motivaciones sociales. Política y sociedad. 53 (1). 17-28. DOI: 10.5209/rev_POSO.2016.v53.n1.48456

Audier, S. (2012). Le Colloque Lippmann. Aux origines du néo-libéralisme. Le Bord de l'eau. Paris.

Ayala-Colqui, J. (2020). Viropolitics and capitalistic governmentality: On the management of the early 21st century pandemic. Desde el Sur. 12 (2). 377-295. DOI: 10.21142/DES-1202-2020-0022

Badiou, A. (2019). Trump. Polity. Cambridge.

Badiou, A. (2020). On the Epidemic Situation. Verso. Recuperado de: https://www.versobooks.com/blogs/4608-on-the-epidemic-situation [Consultado el 7 de noviembre de 2021].

Berardi, F. (2003). La fábrica de la infelicidad. Nuevas formas de trabajo y movimiento global. Traficante de sueños. Madrid.

Biblioteca del Congreso Nacional de Chile (2021). Decreto 100. Fija el texto refundido, coordinado y sistematizado de la Constitución de la República de Chile. Recuperado de: https://www.bcn.cl/leychile/navegar?idNorma=242302 [Consultado el 13 de noviembre de 2021].

Bobbio, N. (2006). Ensayo sobre el fascismo. Prometeo. Buenos Aires. 
Boletín Oficial de la República de Argentina (2020). Legalización y avisos oficiales. Aislamiento social preventivo y obligatorio. Decreto 297/2020. Recuperado de: https://www.boletinoficial.gob.ar/detalleAviso/primera/227042/20200320 [Consultado el 13 de noviembre de 2021].

Boltanski, L. \& Chiapello, É (2002). El nuevo espíritu del capitalismo. Akal. Madrid.

Borón, A. (1977). El fascismo como categoría histórica: en torno al problema de las dictaduras en América Latina. Revista Mexicana de Sociología. 39 (2). 481-528.

Brown, W. (2016). El pueblo sin atributos. La secreta revolución del neoliberalismo. Malpaso. Barcelona.

Butler, J. (2020). Capitalism Has its Limits. Verso. Recuperado de https://www.versobooks.com/blogs/4603-capitalism-has-its-limits [Consultado el 7 de noviembre de 2021]

Cabral, E. (2021). Ultraconservador López Aliaga obtuvo sus votaciones más fuertes en distritos de ingresos altos de Lima. Ojo Público. Recuperado de: https://ojo-publico.com/2636/lopez-aliaga-logrovotaciones-claves-en-distritos-de-ingresos-altos [Consultado el 16 de noviembre de 2021].

Casals, X. (2009). La renovación de la ultraderecha española: una historia generacional (1966-2008). Historia y política. 233-258.

Castro Orellana, R. (2017). Foucault y la resistencia. Una gramática del concepto. Contrastes. Revista Internacional de Filosofía. 12 (1). 45-63. DOI: 10.24310/Contrastescontrastes.v22i1.3413

Cavalcante, S. (2021). A condução neofascista da pandemia de Covid-19 no Brasil: da purificação da vida à normalização da morte. Calidoscópio. 19 (1). 4-17. DOI: 10.4013/cld.2021.191.01

Centenera, M. (2021). La ultraderecha entra en el Congreso de Argentina. El País. Recuperado de: https://elpais.com/internacional/2021-11-15/la-ultraderecha-entra-en-el-congreso-argentino.html [Consultado el 16 de noviembre de 2021].

Chamayou, G. (2018). La société ingouvernable. Une généalogie du libéralisme autoritaire. La Fabrique. Paris.

Constante, A. (2020). La sociedad de la furia. Reflexiones marginales, 8. Recuperado de: https://revista.reflexionesmarginales.com/la-sociedad-de-la-furia/ [Consultado el 13 de noviembre de 2021].

Dardot: \& Laval, C. (2013). La nueva razón del mundo. Ensayo sobre la sociedad neoliberal. Gedisa. Barcelona.

Dardot: \& Laval, C. (2017). La pesadilla que nunca acaba. El neoliberalismo contra la democracia. Gedisa. Barcelona.

Davies, W. (2016). El nuevo neoliberalismo. New left review. 101. 129-143.

Deleuze, G. \& Guattari, F. (1985). El Anti-Edipo. Capitalismo y esquizofrenia. Barcelona. Paidós.

Deleuze, G. \& Guattari, F. (1988). Mil mesetas. Capitalismo y esquizofrenia. Pre-textos. Valencia.

Deleuze, G. (2006). Post-scriptum sobre las sociedades de control. Polis. 13. 1-7. 
Diario Oficial de la República de Chile (2020a). Normas generales CVE 1724518. Recuperado de: https://www.diariooficial.interior.gob.cl/publicaciones/2020/02/08/42574/01/1724518.pdf [Consultado el 13 de noviembre de 2021].

Diario Oficial de la República de Chile (2020b). Normas generales CVE 1742691. Recuperado de: https://www.diariooficial.interior.gob.cl/publicaciones/2020/03/18/42607-B/01/1742691.pdf [Consultado el 13 de noviembre de 2021].

Diario Oficial de la República de Chile (2020c). Normas generales CVE 1743121. Recuperado de: https://www.diariooficial.interior.gob.cl/publicaciones/2020/03/20/42609/01/1743121.pdf [Consultado el 13 de noviembre de 2021].

Diario Oficial de la República de Chile (2020d). Normas generales CVE 1822168. Recuperado de: https://www.diariooficial.interior.gob.cl/publicaciones/2020/09/28/42766/01/1822168.pdf [Consultado el 13 de noviembre de 2021].

Diario Oficial de la República de Chile (2020e). Normas generales CVE 1923351 Recuperado de: https://www.diariooficial.interior.gob.cl/publicaciones/2021/04/06/42922-B/01/1923351.pdf

[Consultado el 13 de noviembre de 2021].

Dornelles, J. (2020). Necrocapitalismo e neofascismo em tempos de peste. Em Brandão, C. \& Dultra, R. Pandemias e pandemônio no Brasil. 90-110. Tirant lo Blanch. São Paulo.

Durán Rojas, C. \& Torres Apablaza, I. (2020). El impasse de la resistencia. La intersección entre Foucault y Deleuze a propósito de la salida del poder. Hybris. Revista de Filosofía,.11 (2). 107-128.

Durand, F. (2019). La captura del Estado en América Latina. Reflexiones teóricas. PUCP. Lima.

El Peruano (2020a). Decreto de urgencia $\mathrm{N}^{\circ} 037-2020$. Recuperado de: https://www.gob.pe/institucion/pcm/normas-legales/473466-037-2020 [Consultado el 13 de noviembre de 2021].

El Peruano (2020b). Decreto legislativo $\mathrm{N}^{\circ}$ 1455. Recuperado de: https://busquedas.elperuano.pe/download/url/decreto-legislativo-que-crea-el-programa-reactiva-perupar-decreto-legislativo-no-1455-1865394-1 [Consultado el 13 de noviembre de 2021].

El Peruano (2020c). Decreto Supremo $\mathrm{N}^{\circ}$ 124-2020-EF. Recuperado de: https://www.gob.pe/institucion/mef/normas-legales/606067-124-2020-e [Consultado el 13 de noviembre de 2021].

El Peruano (2020d). Decreto de urgencia $\mathrm{N}^{\circ}$ 038-2020. Recuperado de: https://busquedas.elperuano.pe/download/url/decreto-de-urgencia-que-establece-medidascomplementarias-pa-decreto-de-urgencia-n-038-2020-1865516-3 [Consultado el 13 de noviembre de 2021].

Ernst, C. \& López, E. (2020). El Covid-19 y el mundo del trabajo en Argentina: impacto y respuestas de la política. Recuperado de: https://aldiaargentina.microjuris.com/wp-content/uploads/2020/04/notatecnoca-ernst.pdf [Consultado el 13 de noviembre de 2021].

Esposito, R. (2006). Bíos. Biopolítica y filosofía. Amorrortu. Buenos Aires.

Fassin, É. (2018). Le moment néofasciste du néolibéralisme. Mediapart. 29 de junio de 2018. Recuperado de: https://blogs.mediapart.fr/eric-fassin/blog/290618/le-moment-neofasciste-duneoliberalisme 
Figueroa, C. \& Moreno, O. (2020). Derecha posneoliberal y neofascismo en América Latina. Bajo el volcán. 2 (3). 77-107.

Foucault, M. (1994a). Dits et écrits (1954-1988), tome III: 1976-1979. Gallimard. Paris.

Foucault, M. (1994b). Dits et écrits (1954-1988), tome IV: 1980-1988. Gallimard. Paris.

Foucault, M. (2000). Defender la sociedad. Curso en el Collège de France (1975-1976). FCE. Buenos Aires.

Foucault, M. (2002). Historia de la sexualidad 1. La voluntad de saber. Siglo XXI. Buenos Aires.

Foucault, M. (2006). Seguridad, territorio, población. Curso en el Collège de France (1977-1978). FCE. Buenos Aires.

Foucault, M. (2007). Nacimiento de la biopolítica. Curso en el Collège de France (1978-1979). FCE. Buenos Aires.

Foucault, M. (2018). ¿Qué es la crítica? Seguido de la cultura de sí. Siglo XXI. Buenos Aires.

Fonseca, A. \& da Silva, S. (2020). Neoliberalismo em Tempos de Pandemia: o Governo Bolsonaro no contexto de crise da Covid-19. Ágora. 22 (2). 58-75.

Guamán, A., Aragoneses, A. \& Martín, S. (dirs.). Neofascismo. La bestia neoliberal. Siglo XXI. Madrid.

Giroux, H. (2018). Neoliberal fascism and the Echoes of History. Truthdig. Recuperado de: https://www.truthdig.com/articles/neoliberal-fascism-and-the-echoes-of-history/

Harvey, D. (2004). El nuevo imperialismo. Akal. Madrid.

Hillani, A. (2021). The Uses of Agamben in pandemic Times. Sociologia e Antropología. 11. 247-257. DOI: $0.1590 / 2238-38752021 v 11$ esp18

Hill Collins: \& Bilge, S. (2019). Interseccionalidad. Morata. Madrid.

Hinkelammert, F. (1984). Crítica de la razón utópica. DEI. San José.

Ignazi: (2003). Extreme Right Parties in Western Europe. Oxford University Press. Oxford.

Kalil, I. (2020). Políticas antiderechos en Brasil: neoliberalismo y neoconservadurismo en el gobierno de Bolsonaro. En Torres, A. (ed.). Derechos en riesgo en América Latina. 11 estudios sobre grupos neoconservadores. 35-53. Fundación Rosa Luxemburgo/Ediciones desde abajo. Quito.

Karmy, R. (2021). La situación fascista en Chile. Teología política y afectividad. Lobo Suelto. Recuperado de: http://lobosuelto.com/la-situacion-fascista-en-chile-teologia-politica-y-afectividadrodrigo-karmy-bolton/ [Consultado el 16 de noviembre de 2021].

Kaya, Ö. (2021). The biopolitics of the covid-19 crisis and a new form of the state of exception. Contemporary Studies in Economic and Financial Analysis. 107. 65-76. DOI: 10.1108/S1569375920210000107012

La Nación (2020). Javier Milei: "Este Gobierno impuso una cuarentena cavernícola y liberticida". Recuperado de: https://www.lanacion.com.ar/espectaculos/javier-milei-este-gobierno-impusocuarentena-cavernicola-nid2469578/ [Consultado el 16 de noviembre de 2021]. 
Lazzarato, M. (2013). La fábrica del hombre endeudado. Ensayo sobre la condición neoliberal. Amorrortu. Buenos Aires.

Lazzarato, M. (2015). Gobernar a través de la deuda. Tecnologías de poder del capitalismo neoliberal. Amorrortu. Buenos Aires.

Lazzarato, M. (2020). ¡Es el capitalismo, estúpido! Recuperado de: http://lobosuelto.com/mauriziolazzarato-es-el-capitalismo-estupido/ [Consultado el 7 de noviembre de 2021].

Lucas, F., Duczmal, L., Steinmetz, W., Leite, A., Leão, J., Camargo, R., Tupinambás, U., Fearnside: (2021). How Brazil's President turned the country into a global epicenter of COVID-19. Journal of Public Health Policy. 42. 439-451.

Marazzi, C. (2014). Capital y lenguaje. Hacia el gobierno de las finanzas. Tinta Limón. Buenos Aires.

Maruy, R. (2019). Sobre la peligrosa idea de un "libre" mercado. Tradición, Segunda época. 19. 46-55. DOI: $10.31381 /$ tradicion.v0i19.2619

Manichkin, N. (2021). Biopolitical aspects of the COVID-19 pandemic: Public discussion about freedom and transformation of social life. Siberian Historical Research. 2021 (2). 141-161. DOI: $10.17223 / 2312461 X / 32 / 7$

Mayta-Tristán: \& Aparco, J. (2021). El uso de un producto de investigación fuera de un ensayo clínico: el caso "Vacunagate". Rev. Peru. Med. Exp. Salud Publica. 38 (2). 203-205. DOI: 10.17843/rpmesp.2021.382.8694

Mbembe, A. (2011). Necropolítica. Melusina. Barcelona.

Mirowski: \& Plehwe, (eds.) (2009). The Road from Mont Pèlerin. The Making of the Neoliberal Thought Collective. Harvard University Press. Cambridge.

Montes, R. (2021). La extrema derecha avanza en la carrera presidencial chilena de la mano de Kast, a siete semanas de las elecciones. El País. Recuperado de: https://elpais.com/internacional/2021-10-09/laderecha-extrema-avanza-en-la-carrera-presidencial-chilena-de-la-mano-de-kast-a-siete-semanas-delas-elecciones.html [Consultado el 16 de noviembre de 2021].

Moruno, J. (2015). La fábrica del emprendedor. Akal. Madrid.

Mudde, C. (2007). Populist radical right parties in Europe. Cambridge University Press. Cambridge.

Negri, A. (2004). Guías. Cinco lecciones en torno a Imperio. Paidós. Barcelona.

Paltrinieri, L. (2017). Managing Subjectivity. Neoliberalism, Human Capital, and Empowerment. Fudan, Journal of the Humanities and Social Sciences. 10 (4). 459-471. DOI: 10.1007/s40647-0170200-0

Pavón-Cuellar, D. (2020). El giro del neoliberalismo al neofascismo: universalización y segregación en el sistema capitalista. Desde el Jardín de Freud. 20. 19-38. DOI: 10.15446/djf.n20.90161

Paxton, R. (2019). Anatomía del fascismo. Capitán Swing. Madrid.

Pele, A. \& Wilson, A. (2020). Brasil e a pandemia de Covid-19: A aposta cínica e genocida de Jair Bolsonaro. Em Brandão, C. \& Dultra, R. (eds.) Pandemias e pandemônio no Brasil. 157-163. São Paulo: Tirant lo Blanch. 
Poulantzas, N. (1976). Fascismo y dictadura. La tercera internacional frente al fascismo. Siglo XXI. España.

Presidencia de la República del Perú (2018). Constitución Política del Perú. Recuperado de: https://www.gob.pe/institucion/presidencia/informes-publicaciones/196158-constitucion-politica-delperu [Consultado el 13 de noviembre de 2021].

Reuters (2020). UPDATE 2-Divisions over Brazil's coronavirus response grow. Retrieved from https://www.reuters.com/article/health-coronavirus-brazil-politics/update-2-divisions-over-brazilscoronavirus-response-grow-idUSL1N2BO0JW

Ríos, C. (2019). A propósito de la noción de "Crítica". O acerca de la imposibilidad de una pedagogía del gesto. Vertientes. Revista de Estudiantes de Filosofía. 1 (1). 24-39.

Ryan, M. (2019). Interrogating "Authoritarian Neoliberalism": The Problem of Periodization. Competition \& Change. 23 (2). 116-137. DOI: 10.1177/1024529418797867

Saad-Filho, A. (2020). De la Covid-19 al fin del neoliberalismo. El trimestre económico, 87 (4), 12111229.

Sacchi, E. (2017). Neoliberalismo, gubernamentalidad y mnemotécnicas de la crueldad. El Arco y la Lira. Tensiones y debates. 5. 47-63.

Sadin, É. (2018). La siliconización del mundo. La irresistible expansión del liberalismo digital. Caja Negra. Buenos Aires.

Saidel, M. (2020). ¿Se puede hablar de un momento fascista del neoliberalismo? Crisis de la democracia liberal y guerra contra las poblaciones precarizadas como síntomas de época. Revista Argentina de Ciencia Política. 1 (24). 70-100.

Salazar, E. (2021). En Perú se extienden acciones de grupos extremistas que desinforman y acosan. Ojo Público. Recuperado de: https://ojo-publico.com/2822/se-extienden-acciones-de-grupos-extremistasque-desinforman-y-acosan [Consultado el 16 de noviembre de 2021].

Silva-Escobar, J. (2021). Biopolítica, necropolítica y pandemia. Notas sobre el neoliberalismo y la desigualdad social en Chile. Autoctonía. 2. 438-453.

Stefanoni: (2021). ¿La rebeldía se volvió de derecha? Cómo el antiprogresismo y la anticorrección política están construyendo un nuevo sentido común (y por qué la izquierda debería tomarlos en serio). Buenos Aires: Siglo XXI.

Stewart: , Garvey, B., Torres, M. \& Borges de Farias, T. (2021). Amazonian destruction, Bolsonaro and COVID-19: Neoliberalism unchained. Capital and class. 45 (2). 173-181. DOI: $10.1177 / 0309816820971131$

Stiegler, B. (2019). «Il faut s'adapter». Sur un nouvel impératif politique. Gallimard. Paris.

Sztulwark, D. (2019). La ofensiva sensible. Neoliberalismo, populismo y el reverso de lo sensible. Caja Negra. Buenos Aires.

Traverso, E. (2016). Espectros del fascismo. Metamorfosis de las derechas radicales en el siglo XXI. Pasajes: Revista de pensamiento contemporáneo. 50. 4-20. Recuperado de: https://roderic.uv.es/handle/10550/57764

Valdes, J. (1995). Pinochet's Economists. The Chicago School of Economics in Chile. Cambridge University Press. Cambridge. 
Velásquez Castro, M. (2020). Hijos de la peste: Historia de las epidemias en el Perú. Taurus. Lima.

Wallace, R., Liebman, A., Chaves, L. \& Wallace, R. (2020). Covid-19 and Circuits of Capital. Retrieved from https://monthlyreview.org/2020/04/01/Covid-19-and-circuits-of-capital/ [Consultado el 7 de noviembre de 2021]. 